index comunicación | no 9 (2) 2019 | Páginas 163-182

E-ISSN: 2174-1859 | ISSN: 2444-3239 | Depósito Legal: M-19965-2015

Recibido el 30_04_2019 | Aceptado el 06_06_2019 | Publicado el 01_07_2019

\title{
VOCES Y DRAMATIZADOS DE REIVINDICACIÓN: LA EXPERIENCIA EN UNA COMUNIDAD RURAL DE ECUADOR
}

VOICES AND DRAMATIZATION OF CLAIMING: AN EXPERIENCE IN A RURAL COMMUNITY IN ECUADOR 
Resumen: El presente trabajo describe cómo la radio y el teatro confluyen en una comunidad rural de Ecuador como instrumentos de reivindicación de las mujeres, visibilizando sus roles en la esfera pública. Mediante una metodología cualitativa de grupos de discusión ellas evidenciaron los discursos de su realidad, enmarcada en una cultura patriarcal que refleja los diferentes rostros de la violencia machista. Esta investigación-acción muestra como resultados que el papel de la mujer como actora social está invisibilizado, que la desigualdad de roles en las actividades del hogar afecta a la la mujer y que esta práctica se marca con fuerza en el discurso hacia los hijos e hijas que viven en estos hogares. Ante esta tesitura se erigen la radio y el teatro en el marco de la educomunicación con un enfoque social y liberador en la lucha por la igualdad de derechos y oportunidades en las relaciones de hombres y mujeres. Palabras clave: radio; teatro; cultura patriarcal; educomunicación; igualdad.

Abstract: This paper describes how radio and theatre joint together in a rural community in Ecuador as instruments for women's rights claiming, highlighting their roles in the public sphere. By means of a qualitative methodology with focus groups, women could show their reality, enclosed in a patriarchal culture that reflects the different faces of violence against women. This action research shows as results that woman's role as a social subject is invisible and that inequality of roles at household chores affects the woman and that this practice is strongly reinforced in the discourse towards sons and daughters at these homes. Given these circumstances, in edu-communication framework, both radio and theatre stand out with a social and liberating approach in the fight for equal rights and opportunities in men and women relationships. Keywords: Radio; Theater; Patriarchal Culture; Edu-communication; Equality. 


\section{Introducción}

Este artículo es el resultado de una investigación-acción desarrollada en 2017 en la comunidad El Ceibo, un recinto rural de la costa ecuatoriana ${ }^{1}$. El trabajo de investigación se realizó con la finalidad de conocer cuál es la función que cumplen la radio y el teatro, como instrumentos de comunicación comunitaria, en un contexto marcado por el dominio patriarcal a las mujeres de esa zona.

El siguiente texto presenta los resultados de esta primera experiencia de comunicación comunitaria y educomunicación en esta zona de la región cinco de Ecuador $^{2}$. Centra su relevancia en que el empleo de la radio y el teatro marcan nuevos derroteros en la construcción de comunidades más igualitarias desde la perspectiva de género.

\subsection{La comunicación comunitaria para el avance en materia de género}

La comunicación comunitaria - comunicación alternativa o comunicación para el desarrollo - nace en Latinoamérica en la década de los años setenta, en oposición a la tendencia dominante de comunicación marcada por el capitalismo y los estereotipos desde las élites hacia las bases sociales.

La comunicación comunitaria es como el paraguas que cubre algunas de las vías o mecanismos que apalancan la participación activa, democrática y de cambio social, a través de una forma horizontal de relación entre unos y otros; es decir, una comunicación que se promueva desde y con las bases sociales.

Gumucio (2004: 02-23) afirma:

La comunicación para el cambio social nace como respuesta a la indiferencia y al olvido, rescatando lo más valioso del pensamiento humanista que enriquece la teoría de la comunicación: la propuesta dialógica, la suma de experiencias participativas y la voluntad de incidir en todos los niveles de la sociedad.

Las herramientas de la comunicación para el cambio social suponen espacios propios de reconocimiento en las propias comunidades. La radio, el teatro, el periódico comunitario, los proyectos de economía social y solidaria, los

${ }^{1}$ El trabajo es parte de un proyecto de investigación global que se llevó a cabo desde la Maestría en Comunicación, mención en Medios Públicos y Comunitarios (2016-2018) de la Universidad Estatal de Milagro (Ecuador).

${ }^{2}$ Ecuador tiene siete zonas en su división administrativa. La zona cinco comprende: Santa Elena, Guayas, Los Ríos, Bolívar y su sede administrativa Milagro. 
documentales comunitarios, desde un enfoque educomunicativo, se erigen como instrumentos de los medios sociales para la participación activa de los ciudadanos y las ciudadanas, quienes elaboran sus propios contenidos desde el olvido de su ruralidad.

Boira, Carbajosa y Méndez (2016) concluyen que las comunidades del territorio rural ecuatoriano se caracterizan porque, en su mayoría, están aisladas, por el débil sistema de las estructuras socioeconómicas, por la precariedad y por la ausencia de recursos.

Estos factores, así como la falta de acceso a la educación, favorecen el entorno en las comunidades rurales para que persista una hegemonía marcada desde tiempos inmemoriales que asienta la voz y el rol en la esfera pública del hombre, en detrimento del rol de la mujer.

Peruzzo (2001) se refiere a los medios de comunicación comunitarios por su doble capacidad de construcción de la ciudadanía, al ofrecer un potencial educativo por el proceso y, además, también por el contenido de los mensajes que transmiten.

Bajo este panorama, desde los medios comunitarios gestados en las bases sociales se abre el camino, implícitamente con la educación, para la reflexión y el empoderamiento de las mujeres en el territorio rural.

\subsection{Educación y Comunicación, sus alcances en la comunidad}

Como señalan González y Tissera (2017), Educación y Comunicación aparecen como independientes, pero se enriquecen mutuamente.

El concepto de Educomunicación se erige sobre la base de dos disciplinas autónomas (Comunicación y Educación), y se sustenta y sostiene en el modelo de educación dialógica propuesto por Paulo Freire en los albores de la década del setenta.

La teoría dialógica de Freire (2012) va en contra de la educación tradicional y la enseñanza de las clases elitistas hacia las clases de las bases sociales. Esta teoría convoca al educando a analizar su entorno y su relación con éste. Es decir, su papel es el de educador y el de educando dentro de ese proceso de reflexión donde la comunicación se convierte en la columna vertebral.

Mayugo (2012: 49-63) relaciona la Educación y Comunicación para facilitar la conexión de cotidianeidades entre los individuos de cada localidad. 
Todo ello — puntualiza - con la intención de que los poderes políicos y económicos les escuchen en lugar de apuntarles lo que se debe hacer y dejar de hacer, lo que se podrá llevar a cabo y lo que no, lo que se le achaca a la base social sin ni siquiera contemplar sus necesidades esenciales.

Esta democratización de la palabra que enfoca Mayugo produce una dinámica participativa de comunicación entre las personas. Tamarit (2012) afirma que esta comunicación colborativa se proyecta en una igualdad de intervención de los participantes, donde los roles de emisor y receptor se intercambian.

Las experiencias en materia de educación y comunicación se vienen desarrollando desde los años setenta y países como Brasil, Colombia, Ecuador, España, México, Argentina y Chile, entre otros, cuentan con este tipo de proyectos encaminados a la democratización de la palabra a través de la radio, la televisión participativa, el arte y las nuevas tecnologías.

Colombia y Bolivia son los dos países en Latinoamérica que muestran en las décadas de los años sesenta y setenta, a través de las radios, un proceso de comunicación de naturaleza participativa.

El primero con procesos de educación popular enfocados hacia la alfabetización con el ejemplo de Radio Sutatenza. El segundo con el manejo y sostenimiento de las radios sindicales mineras, cuya existencia está ligada al grado de avance político-ideológico del sector obrero (Herrera, 2005: 51-58).

Beltrán (2005) describe diferentes escenarios donde la comunicación alternativa ha estado en acción, y destaca a la radio como medio para la comunicación comunitaria por sus bondades técnicas y de alcance. Además, señala las diferentes estrategias comunicativas para la producción de contenidos alternativos, como el caso del «casete foro rural» en Uruguay, las «cabinas telefónicas» en Latacunga, Ecuador, y otras significativas experiencias donde la radio constituyó el elemento de educación para los habitantes de la comunidad.

Hablar de la radio significa hablar de creatividad, de historias, personas, personajes, mundos, que no es posible verlos pero que deben ser visibles por los oyentes. Son ellos y ellas quienes construyen imágenes mentales de lo que se escucha. El lenguaje radiofónico acrecienta su riqueza cuando el teatro confluye en él y se convierte en un medio de protesta, sobre todo para los grupos sociales más vulnerables. 
La «poética del oprimido» de Boal (1980) enfocada en las bases sociales, propone que el mismo espectador asume su rol protagónico, no delega poderes en el personaje, sino que recrea él mismo su rol activo dentro del teatro; a diferencia de lo planteado por Aristóteles y Brecht, donde el espectador se convierte en un ser pasivo al delegar en el personaje las funciones para que lo represente sin contar la vida real.

\subsection{Mujeres en la ruralidad: el radioteatro para concienciar}

La Unesco (1995), en su investigación sobre Analfabetismo y mujeres campesinas e indígenas del Ecuador, sostiene que el acceso a la educación de la mujer campesina está restringido por problemas históricos como la práctica de un trato dispar de la mujer respecto del hombre, en los aspectos civil, social, cultural, político y económico.

El diario El Telégrafo destaca las cifras estadísticas que el Instituto Nacional de Estadística y Censos, INEC (2010), reportó sobre los 5.392.713 habitantes que viven en las áreas rurales y donde el 49,4 por ciento son mujeres que sufren afectaciones por su condición de género.

En la publicación del Encuentro Nacional de Mujeres Rurales del Ecuador «Democracia Paritaria y Agenda 2030» (2017: 22) se expone:

La mayoría de mujeres rurales en el Ecuador vive en un ámbito lleno de carencias y violencia.

Además de tener trabajos fuera del hogar, éstas enfrentan una doble jornada laboral, ya que después del trabajo, llevan la pesada carga de realizar todas las tareas de cuidado y los quehaceres domésticos.

Bajo este panorama, las desigualdades en materia de género que se viven en las comunidades rurales son un escenario de trabajo propicio para la inserción de la radio y el teatro como herramientas de educación y comunicación que, bajo un enfoque de género, busca el empoderamiento de las mujeres y su reivindicación en un mundo de hombres.

Los datos sobre radioteatro en las comunidades rurales de Ecuador escasean en la literatura académica. No obstante, lo que se conoce sobre radioteatro en Ecuador de forma general fue su época dorada (desde 1940 hasta 1965).

Las experiencias educomunicativas de radioteatro con las mujeres rurales resultan un espacio de convivencia, reflexión y lucha social que, además, resucita la cultura de este género radiofónico y contribuye, principalmente, a disminuir las historias de desigualdad que viven las mujeres. 


\section{Metodología}

El trabajo de campo se efectuó en la comunidad El $\mathrm{Ceibo}^{3}$, recinto rural de la costa ecuatoriana en la provincia del Guayas. De acuerdo a datos del INEC (2010), es un área que no supera los 300 habitantes.

La idea de formar un grupo de radioteatro comunitario nació como propuesta de investigación en el Máster en Comunicación —con mención en medios públicos y comunitarios - de la Universidad Estatal de Milagro (Ecuador).

Esta investigación-acción se desarrolló en siete meses, desde mayo hasta noviembre de 2017, con la participación activa de un grupo de once personas (diez mujeres y un hombre). El objetivo del grupo fue el de emplear la radio y el teatro para visibilizar en la esfera pública la realidad de las mujeres mediante la construcción de sus propias historias.

El perfil de las participantes indica una condición socio económica media-baja. Las mujeres desarrollaban el rol de amas de casa y ejercían labores agrícolas (cuidado de parcelas, riego y cosecha de cacao y plátano); algunas de ellas trabajaban cortando el plátano en rodajas para luego freírlo, empaquetarlo y venderlo. En cuanto al nivel de educación, el bachillerato es el nivel educativo que poseen la mayoría de mujeres, no obstante, algunas no finalizaron ni la primaria ni la secundaria.

En la investigación se optó por emplear una metodología cualitativa para el análisis y la interpretación de los discursos. En cuanto a las técnicas de recolección, se hicieron uso de la observación participante, de las entrevistas en profundidad y de los grupos de discusión.

El proceso se desarrolló en tres fases: una primera fase para reconstruir la memoria colectiva de la comunidad; una segunda etapa para el análisis de la realidad de otras mujeres a través de la escucha activa de piezas radiofónicas producidas por la Asociación Radialistas Apasionadas y Apasionados ${ }^{4}$ y una tercera etapa donde a través de la radio y el teatro las mujeres reflejaron su entorno de violencia como el escenario más cercano que viven.

${ }^{3}$ De acuerdo con los datos del Instituto Nacional de Estadística y Censos del Ecuador (INEC), la comunidad El Ceibo es una zona geográfica con un alto nivel de instrucción primaria como último indicio de estudio alcanzado por su población.

${ }^{4}$ La Asociación Radialistas Apasionadas y Apasionados contribuye a la democratización de la palabra mediante la producción de piezas radiofónicas sobre perspectiva de género, derechos y ciudadanía. Su sede funciona en Quito, Ecuador. 
En la primera etapa la observación participante sirvió como una herramienta para detectar el quehacer de los habitantes y, a su vez, para reunir datos sociales y culturales de la zona. Se efectuaron encuentros en los lugares más comunes del sector con el fin de reconstruir la memoria de El Ceibo tras la oralidad de sus habitantes.

Las primeras sesiones de diálogo comunitario convocaron a mujeres, hombres, adolescentes y niños, que paulatinamente desarrollaron una comunicación más interpersonal y compartieron los datos que conocían sobre los orígenes del lugar y cómo se desarrolla la vida en esa comunidad.

Los encuentros sociales se dieron con una periodicidad de dos a tres veces por semana durante seis meses. Se efectuaron entrevistas individuales y grupales al inicio de la primera etapa a las personas con mayor antigüedad en el lugar, que fueron seleccionadas por las participantes del grupo (que meses después sería el grupo de radioteatro $\mathrm{La}$ Voz de El Ceibo).

En las entrevistas individuales las mujeres de la comunidad se organizaron para ubicar a los informantes (fuera y dentro de la comunidad) que contarían los datos históricos de El Ceibo para elaborar el primer guion de radioteatro. A raíz de esto, once personas permanecieron fijas e involucradas en el grupo de radioteatro.

En la segunda y tercera etapa de la investigación-acción se empleó el grupo de discusión como técnica cualitativa para escuchar a las mujeres hablar sobre las situaciones que viven otras mujeres de Ecuador. Los audios que sirvieron como elemento de debate fueron descargados de la web de la Asociación Radialistas Apasionadas y Apasionados.

El grupo de discusión se celebraba una vez a la semana y las participantes colocaban un parlante en la mitad del $\operatorname{lugar}^{5}$ de trabajo, para luego proceder al debate. Los cinco audios seleccionados respondían a temáticas relacionadas con quién maneja el dinero en el hogar y a los diversos rostros de la violencia machista.

La pregunta formulada en el audio — ¿¿y tú qué harías?»— abría el debate donde las mujeres se veían reflejadas por la cercanía de la trama en sus vidas. Esta cercanía les dio el impulso para posicionarse como protagonistas de los audios y generar posibles desenlaces a las historias.

${ }^{5}$ El sitio donde se desarrollaron los grupos de discusión daba mucho juego para que los demás habitantes conocieran las actividades del grupo de radioteatro. Las mujeres se reunían en el patio de una casa cerca de la carretera, al aire libre, con árboles grandes y mucha vegetación. 
En esta última fase, los grupos de discusión se siguieron desarrollando y se construyeron dos historias - Inés, no al maltrato (2017) y Betsaida y Jhon, una historia conocida (2017) — que reflejaban el rol de la mujer y la problemática de violencia machista en la comunidad.

Para la elaboración de las dos producciones finales las mujeres construían la historia inicialmente actuando para luego volcarla al papel (guion). Es decir, dramatizaban cada escena con errores y aciertos hasta que salía la mejor representación y, luego, esas ideas con los diálogos se anotaban en el papel que se convertiría en el guion. Esta fue una dinámica de trabajo que surgió en los últimos encuentros.

El grupo de radioteatro mantuvo un diálogo con la comunidad que acudió a la presentación de estas últimas obras $\mathrm{y}$, previo al cierre de estas, las mujeres del sector realizaron un teatro-foro en torno a las temáticas planteadas.

\section{Resultados}

Los resultados se presentan en dos apartados: el primero describe el proceso inicial del grupo de radioteatro y lo logrado con sus primeras producciones; y el segundo narra la última etapa de la investigación donde la radio y el teatro sirvieron para el análisis de la problemática de violencia contra las mujeres, convirtiéndose, además, en los medios para la representación en la esfera pública.

\subsection{La memoria de EI Ceibo en las primeras producciones}

El primer producto radioteatral Me voy al Ceibo (2017) contó el origen de esta comunidad matizándolo con el quehacer campestre. Luego, se elaboraron dos producciones más: una adaptación de la historia - Martín, el Zapatero ${ }^{6}$ (2017) que describió un lado más humano de la navidad - y, para finalizar esta primera etapa, Un sueño hecho realidad (2017) contó la historia de un grupo de mujeres que, mediante un emprendimiento comercial, se lograron sustentar económicamente y pudieron dar empleo a algunas mujeres de la zona.

\footnotetext{
${ }^{6}$ La historia Martín, el zapatero es de autoría del novelista León Tolstoy. El grupo de radioteatro la adaptó a un contexto rural. La decisión de representar esta obra responde a que ésta había sido dramatizada en otras ocasiones en la iglesia de la comunidad y las mujeres gustaban de darle un sentido espiritual a esta historia. La religión evangélica es acogida por la mayoría de sus habitantes.
} 
En El Ceibo los hombres hacían un mayor uso del espacio público mediante actividades laborales y de ocio, sobre todo los fines de semana. Organizaban áreas para juegos deportivos y de azar que ocupaban algunos de los caminos de esta zona.

Las mujeres, por otra parte, distribuían su tiempo en las tareas del hogar, el cuidado de los hijos e hijas y el trabajo agrícola (quienes cuentan con parcelas a su cargo) hasta los fines de semana. Ellas descansaban habitualmente sentadas fuera de sus casas o algunas miraban la televisión.

La visión machista está enraizada en la comunidad por la transmisión de ésta en las diferentes generaciones. Esta desigualdad de condiciones entre mujeres y hombres es vista con naturalidad por sus habitantes.

Los hombres de la comunidad también fueron invitados a que participaran del grupo de radioteatro o como público invitado en los ensayos; sin embargo, sólo uno se involucró en la investigación. Al hablar con algunos de ellos, se refirieron al proyecto como «cosas de mujeres» y que «les daban permiso» (a las mujeres) para que asistieran a los grupos de discusión.

Las mujeres desvelaban la postura de sus parejas frente a la participación de ellas en el radioteatro; así lo refiere una de las integrantes del grupo: «Algunos esposos se ponen molestos por los dramas (historias)... que no las dejan cocinar, no los atienden a ellos...» (participante $\left.1^{7}, 2017\right)$.

En esta primera etapa las producciones contaban los aspectos cotidianos de la vida en el campo. Ellas, las mujeres, vestidas de campesinos con machete y botas dramatizaban cómo los hombres ocupaban el espacio público después de sus faenas agrarias, ya sea bebiendo cerveza, jugando a las cartas, conversando o diciendo piropos a las mujeres.

La producción Martín, el zapatero versa su trama en la historia de un anciano zapatero que comparte alimento y abrigo con las personas que lo visitan en Navidad. Para esta obra las mujeres se esmeraron en recrear una zapatería. Realizaron una rifa para obtener dinero y comprar una carpa, recogieron zapatos usados de los vecinos y consiguieron, entre ellas, un pedazo de madera que se asemejaba a un martillo remendón para fijar los zapatos.

La producción que cerró esta primera etapa fue Un sueño hecho realidad y aquí las chicas se representaban a ellas mismas, pues esta historia contaba el

\footnotetext{
${ }^{7}$ Considerando el marco ético que contempla toda investigación, los nombres de las informantes han sido protegidos y recibirán la etiqueta de «participante 1,2 , etc».
} 
emprendimiento ${ }^{8}$ que habían tenido hace un año para generar dinero. Ellas relataron cómo iniciaron con el negocio de venta de plátano frito (en rodajas), conocido como «chifle», y el cual es un producto típico de la costa ecuatoriana.

La trama narraba los apuros económicos que vivieron para poder conseguir los instrumentos de cocina, así como los primeros intentos fallidos para levantar un negocio propio. En esta producción las mujeres aprovecharon el final del dramatizado para brindar a la comunidad ese producto que actualmente siguen preparando y que ha servido para aportar en la economía familiar.

Me voy al Ceibo, Martín, el zapatero y Un sueño hecho realidad fueron los primeros dramatizados radiofónicos que sirvieron como elementos de interacción de la comunicación comunitaria. La dinámica de trabajo se tradujo en una necesidad importante de las mujeres por acceder a la educación. Aunque al principio los equipos les generaban un rechazo porque desconocían cómo manipularlos, en cada sesión de trabajo perdían ese recelo a usar los micrófonos y otros instrumentos de audio.

El grupo trabajó para escucharse entre ellas, entender la idea de una comunicación horizontal, conocer y elaborar un guion de radio, identificar las voces y protagonistas de las historias, preparar la indumentaria para las presentaciones y construir y dramatizar sus propios relatos en radio y teatro.

Para este artículo se profundizará en las dos últimas producciones radiofónicas que han sido trabajadas desde una perspectiva de género.

\subsection{Los dramatizados radiofónicos para confrontar la realidad y como herramientas de construcción social}

Escuchar las historias de otras mujeres a través de un parlante no resultó ajeno a las historias de vida del grupo de radioteatro. Los audios de Radialistas Apasionadas y Apasionados motivaron al desahogo y a la reflexión de ellas cuando notaron que lo que vivían también les ocurría a otras mujeres. Una de ellas decidió acabar con el silencio y luego todas fueron compartiendo sus experiencias.

${ }^{8}$ La venta de chifle surgió cuando las mujeres dejaron de recibir el bono de desarrollo humano del Estado (de 50 dólares), por lo que se vieron en la necesidad de generar una fuente para aportar económicamente en sus hogares. Ellas lo intentaron con la venta de plantas y de papas fritas, sin embargo, estos intentos no dieron los resultados esperados. Luego tuvieron la idea de los chifles y ese negocio les ha servido hasta la actualidad para sustentar económicamente sus hogares. 
La participante 2 sostuvo: «Nosotras esperamos los talleres cada semana porque nos liberamos, nos desestresamos de todo el día, aunque nos agarre la noche a veces, pero aquí es donde contamos lo que nos pasa...».

Las historias de Radialistas no tenían un final, pero el narrador dejaba abierto el espacio para la reflexión con la interrogante «¿y tú qué harías?». Esto inquietó a las mujeres, quienes compararon su realidad con la de las mujeres del audio. Ellas se identificaron en el testimonio de la «otra persona», reconocieron que son mujeres que viven situaciones similares y el sigilo se fue yendo ante la imperiosa necesidad de que su discurso fuera escuchado.

Prejuicios, desamparo, abandono, dependencia económica, problemas en el hogar, violencia machista y cultura patriarcal en el hogar fueron algunas de las problemáticas que escucharon y debatieron las mujeres, otorgándoles un fin que rompía con los estereotipos de las historias de amor donde la mujer se sacrifica por la familia.

Uno de los audios narraba la historia de una mujer que se separó de su pareja por los maltratos que recibía de él y éste decide buscarla. Cuando las participantes escucharon este audio, surgió, entre ellas, un final para esa historia y se escuchó lo siguiente: «¡Por qué tiene que darle una nueva oportunidad al marido! ¡Hasta cuándo!» (participante 1, 2017).

Verse reflejadas en otras mujeres y confrontar esa realidad fue el principio de la reivindicación y permitió que los grupos de discusión fueran un espacio esperado por y para ellas.

Las mujeres reconocieron su rol dentro del hogar y lo visibilizaron en la esfera pública mediante la radio y el teatro. Indicaron que la tensión al inicio de los grupos de discusión se dio porque se sentían avergonzadas de contar abiertamente las situaciones de violencia que sufren y que las habían, si no aceptado, sí naturalizado en la relación hombre-mujer.

Al principio no existía esa confianza porque yo pienso ¿por qué voy a estar contándole mis cosas, mis problemas a alguien? Ahora hemos podido desarrollar lo que sentimos, incluso hasta disfrazarnos de hombres porque yo nunca me había disfrazado así (participante 2, 2017).

El abordaje de las temáticas permitió que, durante la discusión, se improvisaran varias escenas tomadas de la vida real para confrontarlas; otorgar una respuesta diferente a la acostumbrada por las mujeres en sus situaciones de violencia. 
Prácticamente el teatro se convirtió en un mecanismo de defensa, en un ensayo de cómo actuar en la vida real ante esa problemática.

Las mujeres de la comunidad que no participaron de la investigación se unían, en algunas ocasiones, a observar los ensayos y entre expresiones alentadoras y aplausos motivaban a las participantes del grupo en el desempeño de los dramatizados.

Las relaciones entre mujeres y hombres de la comunidad El Ceibo y los grupos de discusión visibilizaron el entorno patriarcal en el que ellas se mueven dentro y fuera de sus hogares.

La desigualdad de roles en las actividades del hogar es un discurso que se replica en las generaciones actuales y que continúa construyendo socialmente el rol de sumisión para la mujer y el de hegemonía en el hombre.

El rol que ellas cumplen en casa no es valorado como un trabajo por parte de sus parejas, sino como una tarea propia de ellas durante toda la semana.

Yo he visto muchas cosas aquí de violencia a la mujer que me han hecho llorar... (silencio).

Solamente ha tocado consolar hasta que pase el momento nada más, de ahí ya como vuelve a la normalidad, ya todo se normaliza ya. No se puede denunciar porque está en la familia (participante 3, 2017).

Las dos producciones finales con perspectiva de género fueron trasladadas a la esfera pública bajo un empoderamiento del grupo de mujeres que ya había saltado la barrera del miedo, al sentirse identificadas en las voces de otras mujeres.

El dramatizado Betsaida y Jhon, una historia conocida recoge la historia de una mujer que afronta sola las responsabilidades de su hogar y el cuidado de sus hijos, tras una conducta egoísta y machista de su esposo quien abandona el hogar y los compromisos con su familia. Después de un tiempo decide volver, pero encuentra a una mujer que apostó por una vida digna para ella y sus hijos.

La última producción Inés, no al maltrato enfoca el dominio del hombre sobre la mujer tanto en el espacio privado como en el espacio público. La trama aquí se centra en el silencio desgarrador que lleva Inés con Mario, su pareja, quien la lastima constantemente de forma psicológica. Ella, temerosa, decide escuchar a la dueña de la casa donde trabaja, quien logra empoderarla y romper el ciclo de violencia de su pareja hacia ella.

Las mujeres aspiraban a que los dramatizados finales fueran un escaparate para exponer sus opresiones y contribuyeran a hacer reflexionar a hombres y mujeres sobre el rol de las mujeres de esa localidad. «Por ejemplo, tú ves que unas van a 
diálogos de parejas que hacen en la iglesia del recinto y una ahí solita está...» (participante 1, 2017).

Lo que más coraje da es que tiempo para uno no hay, pero tiempo para sus amistades y borracheras, ahí sí (participante 4, 2017).

La participante 3 (2017) indicó que las situaciones de violencia ocurren dentro de la misma familia y que éstas no podían ser denunciadas por ese lazo familiar que existía.

Es una pena lo que se ve, pero es nuestra realidad. Lo que nos ha tocado vivir y lo viven muchas mujeres (participante 5, 2017).

La participante 4 (2017) recogió la experiencia de teatro del grupo como una buena iniciativa para la comunidad que, además de servir para compartir momentos agradables, permitía llevar un mensaje de reflexión a todos.

Las producciones radiofónicas fueron escuchadas por el grupo al final de cada presentación y la producción de estas piezas representó para ellas un reconocimiento social por parte de la comunidad y para ellas mismas. Este espacio sirvió también para la autocrítica sobre su desempeño en los dramatizados.

El proceso radiofónico tiene un enfoque más alfabetizador en la investigación. Se aprendía en cada etapa, pero hacer uso de sus herramientas y equipos les otorgaba ese carácter formativo, de aprendizaje más que de liberación. La representación teatral que luego realizaban cumplía con ese rol, alfabetizando también, pero con una perspectiva más liberadora.

\section{Discusión}

La comunidad inicialmente entendía la comunicación comunitaria como el asistencialismo de algunas universidades que habían visitado su sector. Es importante reflexionar desde la universidad con el nombre que se da a los proyectos de comunicación con naturaleza asistencialista bajo la etiqueta de Comunicación Comunitaria.

Narváez y Castellano (2018: 25-34) profundizan en el rol del docente universitario que oriente las relaciones sociales con una naturaleza educomunicativa para el aprendizaje entre los sujetos de la educación. 
Voces y dramatizados de reivindicación: la experiencia en... | Sánchez-Cabrera

Hoy más que nunca - escriben- se requiere que el docente se empodere de su responsabilidad en el acontecer comunicativo en el aula y ponga a disposición del estudiante las mediaciones sociales e instrumentales que permitan mejorar la interacción entre los sujetos de la educación y consecuentemente lograr mejores procesos de aprendizaje.

Con este primer proyecto comunitario en la zona rural que aportó alcances significativos en materia de comunicación y género, la educomunicación, queda como un área de estudio para ser explorada desde la academia con el objetivo de fortalecer su potencial ciudadano como actores sociales mediante la educación y la comunicación.

La construcción que sus habitantes tienen en sus distintos roles se ha dado por la cultura arraigada de dominación masculina, donde las actividades se han definido históricamente por el género. Esto se refleja en el espacio público rural de esta comunidad, donde la mujer interviene en el papel reproductivo y las tareas domésticas.

Se reafirma la figura de la mujer en las actividades domésticas y el rol de protagonistas de procesos sociales en espacios públicos, donde el hombre no concibe la actividad de la radio y el teatro como una práctica donde puedan ejercer esa hegemonía que sí la viven en sus espacios de confort.

La dominación masculina de la cual habla Bordieu (2000) sitúa la distribución muy estricta de las actividades asignadas a cada uno de los dos sexos con base en el orden social. Y para este proyecto el orden establecido en la zona rural no deja entrever al hombre como un actor social que contribuya a erradicar este tipo de problemática.

La concepción del rol de la mujer y su visibilización tiene un enfoque hacia el espacio privado, es decir, puertas adentro de sus hogares. Se evidencia una relación directa del rol femenino en la esfera privada concebido a través de la historia, de la familia patriarcal y de la invisibilización de su papel en la conciencia individual de los pobladores.

Aguado (2005) afirma que construir el rol de la mujer en la esfera privada ha significado a su vez el fortalecimiento de todo un sistema patriarcal que engloba lo privado y lo público, estableciendo un orden social con supremacía.

La radio y el teatro como herramientas de la comunicación comunitaria alimentaron esa necesidad comunicacional de la población para su libre expresión. Su aplicación es posible gracias a la participación democrática y al compromiso que 
las personas tienen, haciendo referencia a Peruzzo (2016), como señala Freire (2004) se debe repensar en una comunicación. Un ejercicio de comunicación que convoque a las bases sociales y se informe de la existencia de medios comunitarios, y así poder contar con un sistema de medios fortalecido.

Las políticas públicas para los medios sociales deben responder - no sólo en teoría- a una comunicación de calidad; y en la práctica es cuando deben desarrollar estrategias de información que cubran las zonas menos favorecidas y, así mismo, la difusión de la importancia que tiene una comunicación más democrática e inclusiva en la programación nacional.

La experiencia de $\mathrm{La}$ Voz de El Ceibo logró identificar problemáticas reales de género y construir mediante la comunicación comunitaria miradas diferentes en torno a la multiplicidad de roles que definen a la mujer de esta zona. La educación y la comunicación sirvieron para hacer una lectura de su propia realidad y del reconocimiento de sus capacidades.

Si consideramos el nivel de instrucción educativa de las mujeres de la comunidad El Ceibo, existe un resultado que vislumbra las escasas oportunidades que han tenido para culminar la primaria en algunos casos y, en otros, casi nulos, continuar los estudios superiores; lo que a decir de las mujeres representa una barrera para sentirse reconocidas socialmente y ser generadoras de mayor participación en la toma de decisiones desde sus hogares, mucho más en el espacio público.

Para las mujeres, vivir cada dramatizado radiofónico significó creer en ellas mismas, descubrirse en el relato del otro, construirse socialmente a través de las herramientas de la radio y el teatro, identificar las problemáticas de género y reducir la naturalización en sus vidas e ir empoderándose a través de la educación y la comunicación. Además, poder seguir desarrollando diferentes concepciones sobre su visibilización para que ésta incida en cambios sociales necesarios en la comunidad.

Confirmando lo expuesto por Sosme y Casados (2016) en que el empoderamiento es un proceso que lleva su tiempo y espacio, y no sólo se reduce a una acción, esta práctica comunitaria generó esa oportunidad de empoderamiento a través de la educación y comunicación que permite vislumbrar en ellas una forma de comprensión de su rol y valoración personal.

La metodología en la construcción de los guiones finales rompió con la dinámica empleada en los guiones anteriores. Los grupos de discusión fueron el contexto para producir de forma diferente, no sólo las historias, sino las respuestas a las acciones de violencia machista en sus hogares. Esta forma, como lo señala Boal (1980), es la 
reivindicación de las clases populares ante el poderío de la expresión artística. Como una expresión a lo alto de sus aptitudes y actitudes, las bases sociales construyen sus propias alternativas de comunicación.

Las primeras producciones del proyecto La Voz de El Ceibo asentaron las bases de la comunicación participativa y reconstruyeron la memoria colectiva de esa comunidad que reposaba en los adultos mayores ceibeños, quienes, algunos de ellos, no vivían en el lugar.

Una de las debilidades del proyecto radicaba en el desconocimiento de las mujeres sobre el proceso de edición de las piezas radiofónicas; pese a que ellas las escuchaban y sugerían cambios a las mismas, las mujeres no vivieron ese aprendizaje de edición que implicó más tiempo en días de trabajo y fines de semana. El grupo vivió el proceso de grabación y de reproducción del audio; sin embargo, el quehacer diario de las participantes fue una limitación para el desarrollo de este paso en la producción radiofónica.

La participación activa de las mujeres - también — en el proceso de edición de las piezas es una tarea pendiente para el logro de una mejor y mayor apropiación del aprendizaje de los lenguajes radiofónico y teatral.

Llevar esta propuesta de teatro popular llamada La Voz de El Ceibo a otras comunidades rurales se convierte en un ideal que alimentaría la necesidad comunicacional de las bases sociales y su apuesta por la difusión de sus voces y el reconocimiento de sus discursos.

El grupo La Voz de El Ceibo contempla la posibilidad de continuar activo en futuros proyectos que respondan al cambio social, pues consideran que esto genera en ellas un empoderamiento para reconocerse como actoras sociales de las esferas pública y privada.

\section{Conclusiones}

Lo expuesto hasta aquí enfatiza el proyecto educomunicativo La Voz de El Ceibo como una propuesta que desarrolló el empoderamiento de las mujeres para generar, desde las bases sociales, la necesidad comunicacional en el sector.

Unas necesidades comunicacionales de la población que se ahogan en el silencio de lo cotidiano ante la ausencia de propuestas o proyectos de comunicación colectiva externos que motiven la participación activa de la comunidad.

La carencia de un diálogo del común ha marcado una brecha comunicacional grande que ha mermado el interés de la comunidad para su desarrollo personal y 
colectivo. Esta problemática genera que existan ciudadanos pasivos ante las posibles vulneraciones de sus derechos

Los habitantes intuían que las acciones caritativas o el asistencialismo de las fábricas ubicadas en El Ceibo guardaban una relación directa con la comunicación comunitaria; sin embargo, al final del proyecto identificaron la diferencia entre el asistencialismo que les brindaban con cierta periodicidad las fábricas y el sentido de la comunicación desarrollada con su proyecto.

Existe un campo para la comunicación comunitaria con gran potencialidad para ser explorado y, desde este espacio, se busca llamar a la reflexión a las instituciones de educación superior para que se desarrollen proyectos de comunicación colectiva donde la educomunicación sea la columna vertebral para el desarrollo de la población.

La cultura patriarcal y la violencia machista están arraigadas en El Ceibo, y la población ha normalizado estas acciones en la esfera pública y privada. Con el proyecto se pudo evidenciar en las historias radiofónicas el discurso de las mujeres, no sólo mostrando la problemática que viven, sino también concibiendo la radio y el teatro como elementos de lucha y de transformación de esa realidad.

Las mujeres lograron representar en los dramatizados los roles reproductivo y laboral que cumplen, mediante el relato de cada una, y se afianzaron en sororidad para reconstruirse individual y colectivamente.

La radio y el teatro avivaron en las mujeres del grupo el anhelo de retomar los estudios que, en algunos casos, fueron suspendidos y, en otros, ellas no tuvieron ni el acceso ni las oportunidades. No obstante, aunque la investigación-acción haya traído consigo resultados alentadores en el marco de la comunicación y género, la falta de programas y profesionales de la comunicación comunitaria se convierte en una barrera para la sostenibilidad del proceso de cara al futuro.

La radio y el teatro - herramientas de este proyecto - cumplieron funciones específicas en el grupo. La radio fue un componente más alfabetizador por el aprendizaje de su lenguaje, mientras que el teatro se convirtió en el espacio deseado por ellas para el desahogo de su realidad, como una terapia grupal.

Los resultados de esta investigación nos invitan a repensar en el apoyo a la comunicación liberadora y transformadora de la que nos habló Paulo Freire (2004), como una necesidad imperante para las mujeres que desde las bases sociales gritan en silencio sus historias. 


\section{Bibliografía}

AguAdo, A. (2005). Ciudadanía, mujeres y democracia. Historia Constitucional, 6, 11-27. Recuperado desde: https://bit.ly/2vttEDQ

AlmeIDA, M.; LEIVA, M. y BASTIDA, G. (1995). Investigación de la situación del analfabetismo de la mujer campesina en el Ecuador. Ecuador: Unesco.

BELTRÁN, L. (2006, enero/junio). La comunicación para el desarrollo en Latinoamérica: un recuento de medio siglo. Texto presentado en el III Congreso Panamericano de la Comunicación, Buenos Aires.

BENALCÁZAR, P. (en prensa): Mujer y ruralidad. El Telégrafo.

BOAL, A. (1980). Teatro del Oprimido 1 Teoría y práctica. México: Nueva Imagen.

BoIRA, S.; CARBAJOSA, P. y MÉNDEZ, R. (2016). Miedo, conformidad y silencio, La violencia en las relaciones de pareja en áreas rurales de Ecuador. Psychosocial Intervention, XXV (1), 9-17.

BOURDIEU, P. (2000). La Dominación masculina. España: Anagrama.

FAO; WFP y ONU Mujeres. (2017). Experiencias, desafios y propuestas de las mujeres rurales del Ecuador. Ecuador.

FreIRE, P. (2012). Pedagogía del Oprimido. España: Siglo XXI.

FREIRE, P. (2004). La importancia de leer y el proceso de liberación. México: Siglo XXI.

GONZÁLEZ, F. y TISSERA, V. (2017, octubre). Educomunicación con perspectiva de género: Estrategias para el desarrollo comunitario. Anclaje total a través de proyecto de extensión universitario. Ponencia presentada en las XII Jornadas Nacionales de Investigadores en Comunicación, San Juan.

GuMUCIO, A. (2004). La comunicación para el cambio social. Investigación y Desarrollo, XII (1), 02-23.

HERRERA, K. (2005). Las radios mineras en Bolivia hoy. Mirada diagnóstica a la génesis de la comunicación popular y democrática. Punto Cero, X (11) 51-58.

Instituto Nacional de Estadística y Censos (2010). Recuperado desde: https://bit.ly/2105wRK

NARVÁEZ, A. (2018). Educomunicación hoy: un reto necesario. Rehuso, III (2) 25-34.

Peruzzo, C. (2016). La comunicación en los movimientos sociales y el derecho a la comunicación: señales de un derecho de ciudadanía de quinta generación. Commons, V (2) 8-36. 
Peruzzo, C. (2001). Comunicación comunitaria y educación para la ciudadanía. Signo y Pensamiento, XX (38), 82-93.

SOSME, M. y CASADOS, E. (2016). Etnia y empoderamiento: elementos para el análisis de la transformación de identidades femeninas en la Sierra de Zongolica, Veracruz. Sociológica, XXXI (87) 143-173.

TAMARIT, A. (2012). Las radios comunitarias: entre el compromiso y el espejismo de lo alternativo. En M. MARTínEZ; C. MAYUGO y A. TAMARIT (Coord.). Comunidad y Comunicación Prácticas comunicativas y medios comunitarios en Europa y América Latina (pp. 37-47). España: Fragua Editorial. 